\title{
Impact of an Integrated Community-based Model of Care for Older People with Complex Conditions on Hospital Emergency Presentations and Separations: A Step-wedged Randomized Trial
}

Mann Jennifer ( $\sim$ jennifer.mann@my.jcu.edu.au )

Cairns and Hinterland Hospital and Health Service

Fintan Thompson

James Cook University

Robyn McDermott

University of South Australia

Adrian Esterman

University of South Australia

Edward Strivens

Cairns and Hinterland Hospital and Health Service

\section{Research Article}

Keywords: Older person, Emergency Department, hospital separations, integration, primary care, complexity

Posted Date: March 4th, 2021

DOI: https://doi.org/10.21203/rs.3.rs-265117/v1

License: (c) (i) This work is licensed under a Creative Commons Attribution 4.0 International License. Read Full License

Version of Record: A version of this preprint was published at BMC Health Services Research on July 16th, 2021. See the published version at https://doi.org/10.1186/s12913-021-06668-x. 


\section{Abstract}

\section{Background}

An ageing population and rise in multi-morbidity increase hospital utilisation and acuity of presentation, particularly amongst the older person with complex needs. Health systems must reorient towards preventative and co-ordinated care to reduce hospital demand and achieve positive and fiscally responsible client outcomes. Integrated care models can improve outcomes for the older person by aligning primary practice with the specialist health care and social services required to manage complex needs. This paper describes the impact of a community facing program that integrates care at the primary-secondary interface on the rate of Emergency Department (ED) presentation and hospital separations amongst older people with complex needs.

\section{Methods}

The OPEN ARCH study is a multicentre randomised controlled trial with a stepped wedge cluster design. General practitioners (GPs; $n=14$ ) are considered 'clusters' each comprising a mixed number of participants. 80 community dwelling persons over 70 years of age if non-Indigenous and over 50 years of age if Indigenous were included in the study. Clusters were randomly assigned to the time at which they would commence the OPEN ARCH intervention, with intervention periods of 3, 6 and 9 months duration. Each participant was its own control. ED presentations and hospital separations were collected from Queensland Health Casemix data and analysed with multilevel mixed-effects Poisson regression modelling to determine the effectiveness of the OPEN ARCH intervention. Data were analysed at the cluster and participant levels.

\section{Results}

The OPEN ARCH intervention was found to not make a statistically significant difference to ED presentations or hospitalisations. However, a stabilising of ED presentations and trend toward lower hospitalisation rates over time was observed.

\section{Conclusions}

While this study detected no statistically significant different change in ED presentations or hospital separations, a plateauing of ED presentation and hospitalisation ratesis a clinically significant finding for older persons with complex needs. Multi-sectoral integrated programs of care require an adequate preparation period and sufficient duration of intervention for effectiveness to be measured.

\section{Trial registration}

The OPEN ARCH study received ethical approval from the Far North Queensland Human Research Ethic Committee, HREC/17/QCH/104 - 1174 and is registered on the Australian and New Zealand Trials Registry, ACTRN12617000198325p.

\section{Background}

Health systems are under increasing pressure to reduce potentially preventable hospital demand. $(1,2)$ An ageing population and rise in multi-morbidityincrease hospital utilisation and acuity of presentation, particularly amongst the older person with complex needs. $(1,2)$ Complexity arises from the interface between medical diagnosis (multi-morbidity, frailty, and geriatric conditions) and personal contextual dynamics (socioeconomic status, culture and environment). (3, 4) Complexity increases vulnerability to functional decline and increases the likelihood that an older person will require hospital care. $(1,2,4)$ 
Health systems must reorient towards preventative and co-ordinated care to reduce hospital demand and achieve positive and fiscally responsible client outcomes. $(2,5)$ Preventative care is best delivered in the community by the primary contact physician. $(2,5)$ However, multi-morbidity,geriatric syndromes and psychosocial complexity are often challenging for the General Practitioner to managein isolation. $(6,7)$

Integrated care models can improve outcomes for the older personby aligning primary practice with the specialist health care and social services required to manage complex needs. $(9,10)$ This approach views the General Practitioner (GP) as the central integrating function whereby care continuity is maintained by primary practice and the needs of the individual are addressed comprehensively by an integrated team of collaborators. (11)

Integrated approaches to care for the older person have an established international history.TeWhiringa Ora is a broadly cited community facing model that has shown improvedaccess to health and social care to reduce hospital admission and length of stay in New Zealand. $(12,13)$ In Australia, the Hospital Admission Risk Program (HARP), and Health-One Mt Druitt, also report a decrease in the number of Emergency Department (ED) presentations amongst participants with success of these various models attributed to improved access to primary and specialist health care and communitybased social supports. $(14,15)$

In 2016, The Queensland Department of Health released the Integrated Care Innovation Fund (ICIF)to promote integration between primary care and specialist hospital services (16). The Older Persons Enablement and Rehabilitation for Complex Health Conditions(OPEN ARCH) program was developedin Far North Queensland under this funding arrangement and delivered via a partnership between the Cairns and Hinterland Hospital and Health Service and the North Queensland Primary Health Network.

This paper describes the impact of the OPEN ARCH program on the rate of ED presentations and hospital separationsamongst OPEN ARCH study participants.

\section{Methods}

\section{The OPEN ARCH Intervention}

OPEN ARCH(Older Persons Enablement and Rehabilitation for Complex Health Conditions), provides comprehensive geriatric assessment and client enablement for community dwelling older persons with complex needs.

The intervention is delivered in the primary care setting and features collaboration between the client, treating GP, geriatric specialist and enablement officer (clinical nurse).

Service flow is illustrated in Fig. 1 (17). The OPEN ARCH model of care, study design, recruitment, participants, and data collection methods are described in detail elsewhere and summarised in the remainder of this methods Sect. $(17,18)$

\section{Trial design}

The OPEN ARCH study is a multicentre randomised controlled trial with a stepped wedge cluster design. A stepped wedge trial has random and sequential crossover of clusters from control to intervention. At the first step all of clusters are in the control group, whereas at the end of the final step, all clusters are in the intervention group.

In our study, General practitioners (GPs) were the clusters, each contributing 1-9 participants (clients)to the study. These were randomised at baseline to one of three intervention steps using a simple randomisation method. The step to which each cluster was assigned determined the start date of the intervention for that cluster, with a three-month time period between the commencement of each step. Step One included a three-month control period andnine months of intervention, Step Two a six-month control period and six months intervention, and Step Three included a control period of nine-months followed by three-months of intervention (Fig. 2). 
The OPEN ARCH study received ethics approval from the Far North Queensland Human Research Ethic Committee, HREC/17/QCH/104-1174 and is registered on the Australian and New Zealand Trials Registry, ACTRN12617000198325p. Detail of the trial design is provided in Kinchin et al 2018. (18)

\section{Participants}

Community dwelling persons over 70 years of age if non-Indigenous and over 50 years of age if Aboriginal and/or Torres Strait Islander (Indigenous) were eligible for OPEN ARCH. The lower age requirement for Indigenous participants aligns with Commonwealth Government recognition of the specific health needs of Indigenous persons and the associated eligibility threshold for aged care services (19).Older persons were not eligible if they were, under the care of a geriatrician, receiving a program of co-ordinated care (such as transition care program or nurse navigation), or had a cognitive deficit and no substitute decision maker.

\section{Recruitment}

General Practitioners provided the researchers with a deidentified list of those older personsin their care whom they determined through routine clinical assessmentas having complex needs.Using simple randomisation, the researchers selected up to 12 older persons from each GP who were then approached by their GP and provided verbal consent to be contacted by the OPEN ARCH team.

The Participant Information Form was provided to the participants during a face-to-face meeting with an OPEN ARCH team member prior to the provision of written consent.Participant recruitment was completed over a 7-week period.

\section{Setting}

The OPEN ARCH study was conducted with 14 GPs from 5 GP clinicsin the Cairns and Hinterland region. Two GP clinics were an Aboriginal and Community Controlled Health Organisation. Cairns is located in Far North Queensland, Australia. Theproportion of the Cairns population aged over 65 years is greater than the State average and Aboriginal and Torres Strait Islander persons comprise $14 \%$ of the population (compared to $4 \%$ across the State) (20). In 2014/215 the Cairns region had the highest rate of potentially preventable hospital admissions in the Queensland (20).

\section{Outcome measures}

The number of ED presentations and hospital admissions at the local public health service for each participant was provided by the Cairns and Hinterland Hospital and Health Service from routinely collected health service data within the Casemix data collection system (21). The time periods for these data comprised a three-month period prior to each individual's baseline collection of study measures (i.e. Window 1) and successive three-month periods (i.e. Windows 2-4) prior to each subsequent collection of study measures. For admitted patient data, admissions for blood transfusions and renal dialysis were excluded. Inpatient stays that involved a transfer between wards were combined to create a single episode of care.

Potentially Preventable Hospitalisations (PPHs) were flagged based on primary and secondary International Statistical Classification of Diseases and Related Health Problems, Tenth Revision, Australian Modification (ICD-10-AM) codes. (22)A PPH was identified if the ICD-10-AM codes met the criteria defined in the Australian Institute of Health and Welfare National Healthcare Agreement: PI 18-Selected potentially preventable hospitalisations, 2018. (23) The PPHs were broadly categorised as Vaccine Preventable, Chronic or Acute, although subcategories were also created (e.g. Pneumonia and influenza, vaccinepreventable).

\section{Sample size}

This study aimed for a sample size of 120 participants as outlined in the published study protocol, 
to provide $80 \%$ power anddetect a $9 \%$ difference (effect size) in service utilisationwith statistical significance at the $5 \%$ level. (18)Of the participants identified by their GP as meeting eligibility criteria,92 were randomly selected and invited to participate.

Following enrolment, 12 participants were removed from the study due to withdrawing consent $(n=7)$, commencing support through a separate enhanced care service $(n=4)$ and changing GP $(n=1)$.A total of 80 participants commenced the OPEN ARCH study.

\section{Blinding}

No blinding was undertaken. GPs and patients were required to make an informed decision for consent so had full disclosure of the intervention and the study design. To determine and compare pre- and post-intervention periods for each participant the intervention status was known.

\section{Statistical methods}

The distribution of demographic characteristics, caring status and living situation was compared between Steps at each time window. Age in years, as a median, was compared using Kruskal Wallis H-tests, while categorical variables were compared using Chi Square analyses.

Presentations to the ED and admissions to hospital were count data. Person days in the study was the number of participants, multiplied by the number of days in the study during each time window For example Window 1 was the 90 days prior to baseline data collection, Window 2 was the subsequent 90 days etc. This was calculated as a total for each

GP cluster and time window. In cases where an individual had a hospital separation and/or ED presentation, the length of stay for these events was subtracted from their person days in the study.

The incidence rate of ED presentations and hospital separations were calculated as the number of events divided by the participant days in the study, multiplied by 1,000 .

Rates were compared between Steps using the STATA 'iri' function, which calculates point estimates and confidence intervals for incidence-rate ratios.

To determine the effect of the intervention, after accounting for differences between the Steps, the OPEN ARCH data were transformed into long format by time window and analysed with multilevel mixed-effects Poisson regression modelsusing the STATA 'meqrpossion' function.ED presentationsand hospital separationswere analysed using separate models, each of which had three iterations. The first unadjusted model (Model 1) consisted of a dependent variable (e.g. number of ED presentations) and intervention status (i.e. intervention or control) as the independent variable, with random effects for Step, Cluster and individual. This model was then adjusted for time window (Model 2) to determine whether there were any changes across timeand then adjusted for demographics (Model 3), to account for the differences in patient characteristics between Steps. These mixed effects models were undertaken using an 'Intention to Treat' approach, which assumed that the OPEN ARCH intervention had an immediate effect on rates. For participants in Step 1 for example, events during Window 1 were considered as occurring during a control period and events in Window 2 as during an intervention period. As there was likely a delayed benefit of the intervention, the mixed effects modelling was also undertaken using a 'pragmatic' approach. In this approach, the first window after the intervention commenced was also coded as a control period. In this case, for Step 1, events during both Window 1 and Window 2 were therefore considered as occurring during the control period and Window 3 represented the first intervention period.

All analyses were undertaken using STATA 14 (StataCorp. 2015. Stata Statistical Software: Release 14. College Station, TX: StataCorp LP) and significance was set at 0.05

\section{Results}




\section{Participant flow}

General Practitioners within the OPEN ARCH program identified 111 patients for this study. Of these, 12 were unable to be contacted by the OPEN ARCH research team and 7 did not provide secondary consent for the study.

A total of 92 participants were recruited across 14 GPs (Fig. 3), of which 7 withdrew consent, 4 commenced a geriatricianled memory clinic, and 1 participant changed GP, prior to study commencement and were removed from the study. 80 participants commenced the study and entered Window 2, 77 entered Window 3, 74 entered Window 4, and 72 participants completed the study (Fig. 3). Figure 3 details the reason for individual participant attrition and the associated effect on person-days.

\section{Baseline data}

The baseline characteristics of OPEN ARCH participants is described with in detail elsewhere. (24) In summary, there were more females (55\%) than males, more than half the participants were aged over 80 years (56.3\%) and approximately $15 \%$ of participants identified as Indigenous. More than half the participants did not have a carer (56.3\%) and almost all (92\%) were in receipt of a pension.

Demographic characteristics were collected from participants at baseline only. As such, caring and living situation of each participant were assumed to have not changed over the duration of the study. There was no significant difference in age, gender or living situation between steps and this remained true over time (Table 1). A significant difference between steps was noted for Indigenous status ( $p=0.025)$, and the presence of a family carer $(p=0.02)$ with significance maintained for each characteristic across time windows(Table 1).

In the first time window (Window 1) 11 participants (13.8\%) had an ED presentation during the first and 12 (15.0\%) a hospital separation. 
Table 1

- Characteristics of participants in the OPEN ARCH study, by visit

\begin{tabular}{|c|c|c|c|c|c|}
\hline \multirow[t]{2}{*}{ Measure } & \multirow[t]{2}{*}{ Step } & \multicolumn{4}{|l|}{ Window } \\
\hline & & 1 & 2 & 3 & 4 \\
\hline \multirow{3}{*}{$\begin{array}{l}\text { Number } \\
\text { (Participants per Window) }\end{array}$} & 1 & 29 & 29 & 28 & 26 \\
\hline & 2 & 26 & 26 & 25 & 25 \\
\hline & 3 & 25 & 25 & 24 & 23 \\
\hline \multirow{3}{*}{$\begin{array}{l}\text { Age (years) } \\
\text { Median (IQR) }\end{array}$} & 1 & 79 (77-84) & 79 (77-84) & 79 (77-84) & 79 (77-84) \\
\hline & 2 & $78.5(74-87)$ & $78.5(74-87)$ & $78(74-87)$ & $78(74-87)$ \\
\hline & 3 & $83(80-86)$ & $83(80-86)$ & $83.5(79.5-86)$ & $84(80-86)$ \\
\hline \multicolumn{2}{|l|}{ Kruskal Wallis [Chi, P] } & {$[3.04,0.219]$} & {$[3.04,0.219]$} & {$[2.85,0.240]$} & {$[2.99,0.225]$} \\
\hline Male & 1 & $34.5(17.2-51.8)$ & $34.5(17.2-51.8)$ & $35.7(18.0-53.5)$ & $30.8(13.0-48.5)$ \\
\hline \multirow[t]{2}{*}{ Percent (95\% Cl) } & 2 & $53.8(34.7-73.0)$ & $53.8(34.7-73.0)$ & $56.0(36.5-75.5)$ & $56.0(36.5-75.5)$ \\
\hline & 3 & $48.0(28.4-67.6)$ & $48.0(28.4-67.6)$ & $45.8(25.9-65.8)$ & $47.8(27.4-68.2)$ \\
\hline \multicolumn{2}{|l|}{ Chi Squared [Chi, P] } & {$[2.21,0.331]$} & {$[2.21,0.331]$} & {$[2.19,0.334]$} & {$[3.42,0.180]$} \\
\hline \multirow{3}{*}{$\begin{array}{l}\text { Indigenous } \\
\text { Percent ( } 95 \% \mathrm{Cl})\end{array}$} & 1 & $20.7(5.9-35.4)$ & $20.7(5.9-35.4)$ & $21.4(6.2-36.6)$ & $19.2(4.1-34.4)$ \\
\hline & 2 & $23.1(6.9-39.3)$ & $23.1(6.9-39.3)$ & $24.0(7.3-40.7)$ & $24.0(7.3-40.7)$ \\
\hline & 3 & 0.0 & 0.0 & 0.0 & 0.0 \\
\hline \multicolumn{2}{|l|}{ Chi Squared [Chi, P]* } & {$[6.48,0.025]$} & {$[6.48,0.025]$} & {$[6.50,0.025]$} & {$[6.06,0.032]$} \\
\hline \multirow{3}{*}{$\begin{array}{l}\text { Family Carer } \\
\text { Percent }(95 \% \mathrm{Cl})\end{array}$} & 1 & $27.6(11.3-43.9)$ & $27.6(11.3-43.9)$ & $28.6(11.8-45.3)$ & $23.1(6.9-39.3)$ \\
\hline & 2 & $46.2(27.0-65.3)$ & $46.2(27.0-65.3)$ & $48.0(28.4-67.6)$ & $48.0(28.4-67.6)$ \\
\hline & 3 & $12.0(-0.7-24.7)$ & $12.0(-0.7-24.7)$ & $8.3(-2.7-19.4)$ & $8.7(-2.8-20.2)$ \\
\hline \multicolumn{2}{|l|}{ Chi Squared [Chi, P]* } & {$[12.22,0.020]$} & {$[12.22,0.020]$} & {$[14.49,0.006]$} & {$[14.64,0.006]$} \\
\hline \multirow{3}{*}{$\begin{array}{l}\text { Lives with Family } \\
\text { Percent }(95 \% \mathrm{Cl})\end{array}$} & 1 & $17.2(3.5-31.0)$ & $17.2(3.5-31.0)$ & $17.9(3.7-32.0)$ & $15.4(1.5-29.3)$ \\
\hline & 2 & $23.1(6.9-39.3)$ & $23.1(6.9-39.3)$ & $24.0(7.3-40.7)$ & $24.0(7.3-40.7)$ \\
\hline & 3 & $12.0(-0.7-24.7)$ & $12.0(-0.7-24.7)$ & $12.5(-0.7-25.7)$ & $13.0(-0.7-26.8)$ \\
\hline \multicolumn{2}{|l|}{ Chi Squared [Chi, P]* } & {$[2.92,0.574]$} & {$[2.92,0.574]$} & {$[3.50,0.471]$} & {$[3.58,0.457]$} \\
\hline
\end{tabular}

Table 2 shows total the rate of ED presentations in the Intervention period $(2.52,95 \% \mathrm{Cl} 2.48-4.48)$ was comparable to the rate in the Control period $(2.80$ per $1,000,95 \% \mathrm{Cl} 1.99-2.82, \mathrm{IRR}=0.09,95 \% \mathrm{Cl} 0.66-1.27, \mathrm{p}=0.254)$. While the total rate of Hospital Separations was slightly lower in the Intervention period $(2.59,95 \% \mathrm{Cl} 1.83-3.55)$ compared to the Control period $(3.37,95 \% \mathrm{Cl} 1.78-3.48)$, the difference was only at trend significance $(\mathrm{IRR}=0.77,95 \% \mathrm{Cl} 0.58-1.05, \mathrm{p}=0.080)$. 
Table 2

-Person days, ED Presentations and Hospital Separations expressed as rates for participants in the OPEN ARCH study by Step, differences between intervention and control periodsanalysed Incident Rate Ratios (IRR)

\begin{tabular}{|c|c|c|c|}
\hline & Person days & ED Presentations & Hospital Separations \\
\hline \multicolumn{4}{|c|}{ Control Period } \\
\hline \multicolumn{4}{|l|}{ Step 1} \\
\hline Window 1 & 2585 & 6 & 4 \\
\hline \multicolumn{4}{|l|}{ Step 2} \\
\hline Window 1 & 2276 & 13 & 14 \\
\hline Window 2 & 2327 & 6 & 10 \\
\hline \multicolumn{4}{|l|}{ Step 3} \\
\hline Window 1 & 2240 & 3 & 3 \\
\hline Window 2 & 2558 & 9 & 9 \\
\hline Window 3 & 1953 & 2 & 7 \\
\hline Total & 13939 & 39 & 47 \\
\hline Rate & & 2.80 & 3.37 \\
\hline $95 \% \mathrm{Cls}$ & & $(1.99-3.82)$ & $(1.78-3.48)$ \\
\hline \multicolumn{4}{|c|}{ Intervention Period } \\
\hline \multicolumn{4}{|l|}{ Step 1} \\
\hline Window 2 & 2784 & 8 & 6 \\
\hline Window 3 & 2545 & 4 & 4 \\
\hline Window 4 & 2148 & 3 & 5 \\
\hline \multicolumn{4}{|l|}{ Step 2} \\
\hline Window 3 & 2464 & 9 & 8 \\
\hline Window 4 & 2170 & 8 & 8 \\
\hline \multicolumn{4}{|l|}{ Step 3} \\
\hline Window 4 & 2561 & 5 & 7 \\
\hline Total & 14672 & 37 & 38 \\
\hline Rate & & 2.52 & 2.59 \\
\hline $95 \%$ Cls & & $(2.48-4.48)$ & $(1.83-3.55)$ \\
\hline \multicolumn{4}{|c|}{ Incidence Rate Ratio (IRR) } \\
\hline IRR & & 0.90 & 0.77 \\
\hline $95 \% \mathrm{Cls}$ & & $(0.66-1.27)$ & $(0.58-1.05)$ \\
\hline 1 sided $p$ & & 0.254 & 0.040 \\
\hline
\end{tabular}




\begin{tabular}{|llll|}
\hline & Person days & ED Presentations & Hospital Separations \\
\hline 2 sided $\mathrm{p}$ & 0.508 & 0.080 \\
\hline
\end{tabular}

Mixed effects modelling using the Intention to Treat approachindicated no effect of the intervention on ED presentations (Model 1- IRR $=0.91,95 \% \mathrm{Cl} 0.56-1.47, \mathrm{p}=0.697$ ). This result remained stable after adjusting for time period (Model 2IRR $=1.35,95 \% \mathrm{Cl} 0.57-3.17, \mathrm{p}=0.498$ ) and demographics (Model $3-\mathrm{IRR}=1.17,95 \% \mathrm{Cl} 0.52-2.66, \mathrm{p}=0.703)(\mathrm{Table} 3) . \mathrm{A}$ similar trend was observed for hospital separations. When all mixed effects analyses were undertaken using a'pragmatic approach', there remained no effect from the intervention (results not tabled).

Table 3

Multilevel mixed-effects Poisson regression modelling with Incident Rate Ratios (IRR) for ED Presentations and Hospital Separations, unadjusted and adjusted for time period and demographics
Model 1
Model 2
Model 3

$\begin{array}{lllllllll}\text { IRR } & (95 \% \mathrm{Cl}) & \mathrm{P} & \mathrm{IRR} & (95 \% \mathrm{Cl}) & \mathrm{P} & \text { IRR } & (95 \% \mathrm{Cl}) & \mathrm{P}\end{array}$

ED Presentations

\begin{tabular}{|c|c|c|}
\hline Intervention Status & 0.91 & \\
\hline
\end{tabular}

Time Period

1 (ref)

\begin{tabular}{lllllll}
$\mathbf{2}$ & 0.88 & $(0.46-1.70)$ & 0.709 & 0.91 & $(0.47-1.76)$ & 0.787 \\
\hline 3 & 0.58 & $(0.22-1.51)$ & 0.263 & 0.64 & $(0.25-1.66)$ & 0.361 \\
\hline 4 & 0.60 & $(0.20-1.79)$ & 0.361 & 0.69 & $(0.24-1.97)$ & 0.484 \\
\hline Indigenous Status & & & & 2.27 & $(0.63-8.14)$ & 0.208 \\
\hline Age & & & & 0.97 & $(0.91-1.04)$ & 0.417 \\
\hline Gender & & & & 0.74 & $(0.33-1.63)$ & 0.451
\end{tabular}

Hospital Separations

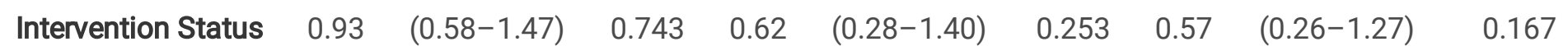

Time Period

1 (ref)

\begin{tabular}{lllllll}
$\mathbf{2}$ & 1.23 & $(0.67-2.27)$ & 0.499 & 1.26 & $(0.68-2.32)$ & 0.457 \\
\hline $\mathbf{3}$ & 1.48 & $(0.64-3.46)$ & 0.36 & 1.59 & $(0.68-3.69)$ & 0.283 \\
\hline $\mathbf{4}$ & 1.90 & $(0.68-5.34)$ & 0.224 & 2.07 & $(0.74-5.75)$ & 0.165 \\
\hline Indigenous Status & & & & 2.41 & $(0.53-10.87)$ & 0.252 \\
\hline Age & & & & 0.97 & $(0.90-1.05)$ & 0.443 \\
\hline Gender & & & & 0.80 & $(0.32-1.99)$ & 0.627
\end{tabular}

Notes: Model 1 - Unadjusted, Model 2 - Adjusted for time period, Model 3 - Adjusted for time period, Indigenous status, age and gender.

Potentially Preventable Hospitalisations 
There were 13 hospital admissions identified as PPHs during the study, and these were spread almost evenly between the time windows and across the intervention groups (data not tabled). The most common diagnoses were Chronic Bronchitis (J44.11, $n=3)$, Chronic Obstructive Pulmonary Disease (J44.0, $n=3)$ and Congestive Cardiac Failure $(I 50.0, n=2)$. As there were only a small number of PPHs, no further analyses were undertaken.

\section{Harms}

There were no harms reported in this trial.

\section{Discussion}

The OPEN ARCH intervention was designed to integrate health services at the primary-secondary interface in a preventative and comprehensive approach to geriatric care. The aim of this study was to determine whether the OPEN $\mathrm{ARCH}$ intervention influenced the rate of ED presentation or hospital separation of study participants. The results indicate that the OPEN ARCH intervention did not make a statistically significant difference to the primary outcomes. However, a stabilising of ED presentations and trend toward lower hospitalisation rates while not statistically significant (at the $5 \%$ level) are clinically important findings as functional decline and a related increase innon-preventable hospital utilisation could be expected within this population group over time. $(1,3)$

Although the stepped wedge RCT has been implemented elsewhere as a robust method of health service evaluation (25), the short trial period of the OPEN ARCH study and the low participant numbers were considerable limitations that impacted the capacity for the study to show effect. The malalignment of research requirements and project deliverables is of note here.

Fixed term project funding plus a substantial set-up period eroded the intervention periodand compromised the capacity for extensive participant recruitment.

These limitations are similar to those reported in the first round of Australian Coordinated Care trials.In these trials, brief project timeframes and limitations in evaluation design compromised the capacity for the intervention to measure benefit to participants. (26)These same constraints were alsoidentified as key factors in the failure of other integrated care programs to show effect. (27)

Despite the noted limitations, OPEN ARCH is the onlyAustralian-basedprogram of its kind (i.e. integrating geriatric care at primary-secondary interface)that has evaluatedthe impact on hospital utilisation via a randomised controlled trial. While other similar Australian integrated care programs have reported a positive impact on ED presentations and hospitalisations (HART reported a $20.8 \%$ reduction in ED presentations and a $27.9 \%$ reduction in hospital admissions,andHealthOne Mt Druitt reported a significant difference in ED presentations amongst participants) each of these interventions utilised a pre-post design and neither included a comparator group. $(14,15)$

As a preventatively focussed program of care, OPEN ARCH sought to intervene early in the trajectory of the participant's illness and did not include the frequency of ED presentation or hospitalisation as eligibility criteria.

As such, only 11 participants (13.8\%) had an ED presentation during the first time window and $12(15.0 \%)$ a hospital separation.

This contrasts withboth HARPand HealthOne Mt Druitt in which participants having at least three ED presentations in the 12 months prior to program enrolment was an eligibility criteria.

$(14,15)$ The lower numbers of individuals presenting to ED or being admitted in the OPEN ARCH study means that a significant impact on these measures would be difficult to show in the time period and may represent a less vulnerable cohort than HARP or HealthOne. 
Literature suggests that comprehensive evaluation of integrated and community focussed models of care must include both patient reported outcome and evaluation measures $(27,28)$. The study reported here is only one component of the larger OPEN ARCH evaluation in which the patient experience has been explored with positive results, and patient reported outcome measures of function and quality of life will be examined. $(18,29)$

\section{Conclusion}

Results indicate that while this study detected no statistically significant different change in ED presentations or hospital separations, stabilising of ED presentation and hospitalisation rates is a clinically significant finding for older persons with complex needs. However, a longitudinal perspective is required to determine longer term impact. The complexity of implementing integrated approaches to care must be considered when planning the evaluation of such programs. A multifaceted approach to the evaluation of integrated care interventions that includes patient reported outcome and experience measures is essential to accurately determine effectiveness of the intervention.

\section{Declarations}

\section{Ethics approval and consent to participate}

The OPEN ARCH study received ethical approval from the Far North Queensland Human Research Ethic Committee, HREC/17/QCH/104 - 1174 and is registered on the Australian and New Zealand Trials Registry, ACTRN12617000198325p. All methods were performed in accordance with the relevant guidelines and regulations including the consenting of participants to the study.

\section{Consent for publication}

Not applicable

\section{Availability of data and materials}

The datasets generated and/or analysed during the current study will be made available on request with the appropriate ethics and governance North Queensland Primary Health Network.

\section{Authors' contributions}

JM and ES developed the study protocol. JM organised and supervised the data collection. JM and FT audited the quality of data. AE advised and supervised the data analysis. FT performed the data analysis. JM and RM interpreted the results. JM and FT drafted the manuscript. All authors critically reviewed and approved the final manuscript.

\section{Acknowledgements}

The authors would like to thank the OPEN ARCH steering committee and data collectors as well as the General Practitioners and older persons who agreed to partner with OPEN ARCH in this study.

\section{Conflict of interest}


JM and ES are members of the OPEN ARCH service delivery team.

\section{Funding}

This study received funding joint funding from Queensland Health and the North Queensland Primary Health Network.

\section{References}

1. McPake B. \& Mahal A. Addressing the Needs of an Ageing Population in the Health System: The Australian Case. Health Systems and Reform. 2017:3(3): 236-248.

2. Katterl, R. Anikeeva O., Butler C., Brown L., Smith B., Bywood P. Potentially avoidable hospitalisations in Australia: Causes for hospitalisations and primary health care interventions. [Internet]. Primary Health Care Research \& Information Service: PHCRIS Policy Issue Review. 2012. Available from:

https://dspace.flinders.edu.au/xmlui/bitstream/handle/2328/26600/PIR\%20July\%202012\%20Full.pdf? sequence=1\&isAllowed=y [cited 2021 Feb 2].

3. Beswick, A.D., Rees K., Dieppe P., Avis S., Gooberman-Hill R., Horwood J., Ebrahim S.Complex interventions to improve physical function and maintain independent living in elderly people: a systematic review and meta-analysis. 2008:371(9614): 725-35.

4. Agency for Clinical Innovation. Building Partnerships: A framework for integrating care for older people with complex health needs. [Internet] New South Wales Department of Health. 2014. Available at:

https://www.aci.health.nsw.gov.au/_data/assets/pdf_file/0003/249483/Building_Partnerships_Framework.pdf[cited 2021 Feb 2]

5. Tieman, J., Mitchell, G., Shelby-James, T., Currow, D., Fazekas, B., O’Doherty L., Hegarty M., Erikkson L., Brown R., ReidOrr D. Integration, coordination and multidisciplinary care: what can these approaches offer to Australian primary health care?. Australian Journal of Primary Health. 2007:13: 56-6.

6. Kuipers P., Kendall E., Ehrlich C., Amsters., Kendall M., Kuipers K., Muenchberger H., Brownie S. Complexity and healthcare: health practitioner workforce services, roles, skills and training to respond to patients with complex needs. [Internet].Clinical Education and Training Queensland. 2011. Available at: https://www.health.qld.gov.au/_data/assets/pdf_file/0027/150768/complexcarefull1.pdf [cited on 2021 Feb 2]

7. Pond D. C., Regan C. Improving the delivery of primary care for older people. [Internet]. Med J Aust. 2019;21(2):6062.e1.doi: $10.5694 / \mathrm{mja} 2.50236$

8. Herzog A., Gaertner B., Scheidt-Nave C., Holzhausen M. 'We can only do what we have the means for' General Practitioners' views of primary care for older people with complex health problems. [Internet]. BMC Family Practice. 2015:16(35). DOI 10.1186/s1287-015-0249-2.

9. Mitchell G.K., Burridge, L., Zhang, J., Donald, M., Scott, I. A., Dart, J. Jackson, C. L. Systematic review of integrated models of health care delivered at the primary-secondary interface: how effective is it and what determines effectiveness? Australian Journal of Primary Health. 2015:21(4):391-408.

10. Integrated care for older people: guidelines on community-level interventions to manage declines in intrinsic capacity. [Internet]. Geneva: World Health Organization. 2017. Licence: CC BY-NC-SA 3.0 IGO. Accessed at: https://apps.who.int/iris/bitstream/handle/10665/258981/9789241550109eng.pdf;jsessionid=E5EC73932300AB013FDFFF43EF72E02E? sequence=1 [cited on 2021 Feb 2].

11. Valentijn P. P., Schepman S. M., Opheij W., Bruijnzeels M. A. Understanding integrated care: a comprehensive coneptual framework based on the intgrative functions of primary care. [Internet] International Journal of Integrated Care. 2013:13.URN:NBN:NL:Ul:10-1-114415

Page $12 / 16$ 
12. Carswell P. Te Whiringa Ora: person-centred and integrated care in the Eastern Bay of Plenty, New Zealand. [Internet] International Journal of Integrated Care. 2015:15. URN:NBN:NL:Ul:10-1-114820.

13. Wodchis W. P., Dixon A., Anderson G. M., Goodwin N. Integrating care for older people with complex needs; key insignts and lessons from a seven-country cross-case analysis. [Internet]. International Journal of Integrated Care. 2015: Available at https://www.ijic.org/articles/10.5334/ijic.2249/ [cited on 2021 Feb 02].

14. Bird, S.R., Kurowski, W., Dickman, G.K. and Kronborg, I. Integrated care facilitation for older patients with complex health care needs reduces hospital demand. Australian Health Review. 2007:31(3):451-461.

15. McNab, J., Mallitt, K. and Gillespie, J. Report of the evaluation of HealthOne Mount Druitt. [Internet]. Menzies Centre for Health Policy. 2013. Available at https://ses.library.usyd.edu.au/bitstream/handle/2123/8988/HOMDevaloct13.pdf [cited on 2021 Feb 2]

16. State of Queensland. Integrated Care Innovation Fund. 2019. Available at https://www.health.qld.gov.au/improvement/make-it-happen/integrated-care-innovation-fund [cited on 2021 Feb 2]

17. Mann J., Quigley R., Harvey D., Tait M., Williams G., Strivens E. OPEN ARCH: Integrated care at the primary-secondary interface for the community-dwelling older person with complex needs. [Internet]. Australian Journal of Primary Health. 2020.26(2).Available at: https://doi: 10.1071/PY19184[cited on 2021 Feb 2].

18. Kinchin I., Jacups S., Mann J., Quigley R., Harvey D., Doran C. M., Strivens E. Efficacy and cost-effectiveness of a community -based model of care for older patients with complex needs: a study protocol for a multicentre randomised controlled trial using a stepped wedge cluster design. [Internet]. Trials. 2018:19(668). Available at: https://doi.org/10.1186/s13063-018-3038-0 [cited on 2021 Feb 2].

19. Australian Institute of Health and Welfare. The health and welfare of Australia's Aboriginal and Torres Strait Islander peoples: 2015. [Internet] AlHW. Available at: https://www.aihw.gov.au/reports/indigenous-health-welfare/indigenoushealth-welfare-2015/contents/table-of-contents [cited on $2021 \mathrm{Feb} 2$ ].

20. Queensland Government. Cairns and Hinterland Hospital and Health Service Clinical Service Plan 2018-2022. [Internet]. State of Queensland, Cairns and Hinterland Hospital and Health Service. 2018. Available at : https://www.health.qld.gov.au/_data/assets/pdf_file/0036/695358/csp-web-spreads.pdf [cited on 2021 Feb 2].

21. Queensland Health Casemix and Clinical Costing, Supporting Services. [Internet] 2010. Available at: https://www.health.qld.gov.au/redcliffe/work/ss-casemix [cited on 2021 Feb 2].

22. World Health Organization. International Statistical Classification of Diseases and Related Health Problems 10threvision, 2 ${ }^{\text {nd }}$ Available at: https://apps.who.int/iris/handle/10665/42980 [cited on 2021 Feb 2].

23. Australian Institute of Health and Welfare. National Healthcare Agreement: PI 18-Selected potentially preventable hospitalisations. [Internet]. AlHW. 2018. Accessed at: https://meteor.aihw.gov.au/content/index.phtml/itemld/658499 [cited on 2021 Feb 2].

24. Mann J., Thompson F., Quigley R., McDermott R., Devine S., Strivens E. Beyond multimorbidity: primary care and the older person with complex needs. [Internet]. Australian Journal of Primary Health. 2021. Available at:https://doi.org/10.1071/PY20125 [cited on 2021 Feb 12].

25. Mitchell G. K., Burridge L., Zhang J., Donald M., Scott I.A., Dart J., Jackson C. L. Systematic review of integrated models of health care delivered at the primary-secondary interface: how effective is it and what determines effectiveness. [Internet]. Australian Journal of Primary Health. 2019:21(4):391-408. Available at:https://doi.org/10.1071/PY14172 [cited on $2021 \mathrm{Feb} 2]$.

26. Esterman, A.J. and Ben-Tovim, D.I. The Australian Coordinated Care Trials: success of failure?The second round of trials may provide more answers. Medical Journal of Australia. 2002:177:469-470.

27. Kumpunen S., Edwards N., Georghiou T., Hughes. Evaluating integrated care. Why are evaluations not producing the results we expect? Briefing Paper November 2019. [Internet] Nuffield Trust. Available at 
https://www.nuffieldtrust.org.uk/files/2019-11/the-challenges-of-evaluating-integrated-care-briefing-3.pdf [cited on 2021 Feb 2].

28. Stoop A, Lette M, Ambugo EA, Gadsby EW, Goodwin N, Maclnnes J, et al. Improving Person-Centredness in Integrated Care for Older People: Experiences from Thirteen Integrated Care Sites in Europe. [Internet]. International Journal of Integrated Care. 2020:20(2):16. Available at:http://doi.org/10.5334/ijic.5427[cited on 2021 Feb 2].

29. Quigley R., Russell S., Harvey D., Mann J. OPEN ARCH integrated care model: experiences of older Australian and their carers. Australian Journal of Primary Health. In press.

\section{Figures}

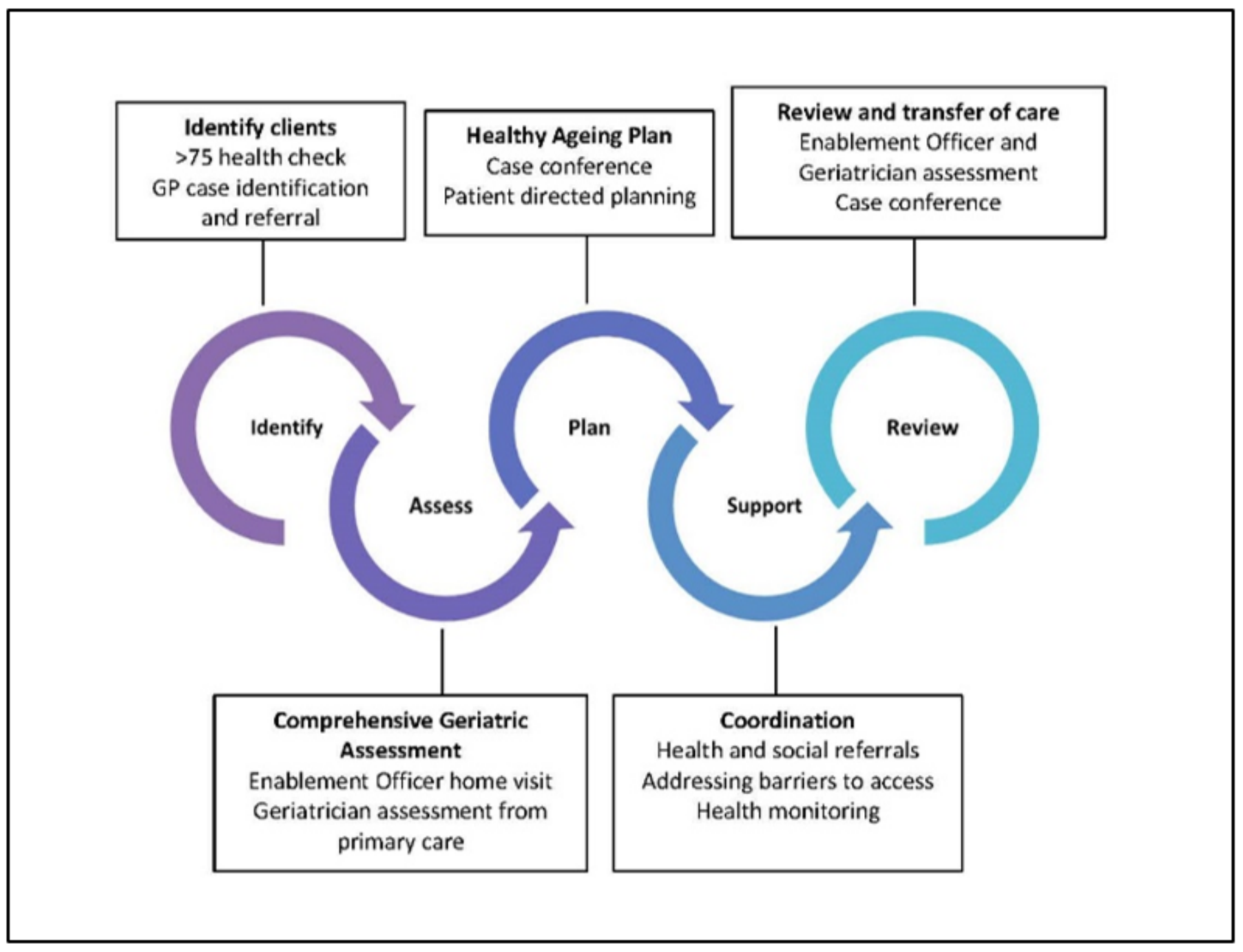

Figure 1

Service flow of the OPEN ARCH intervention 


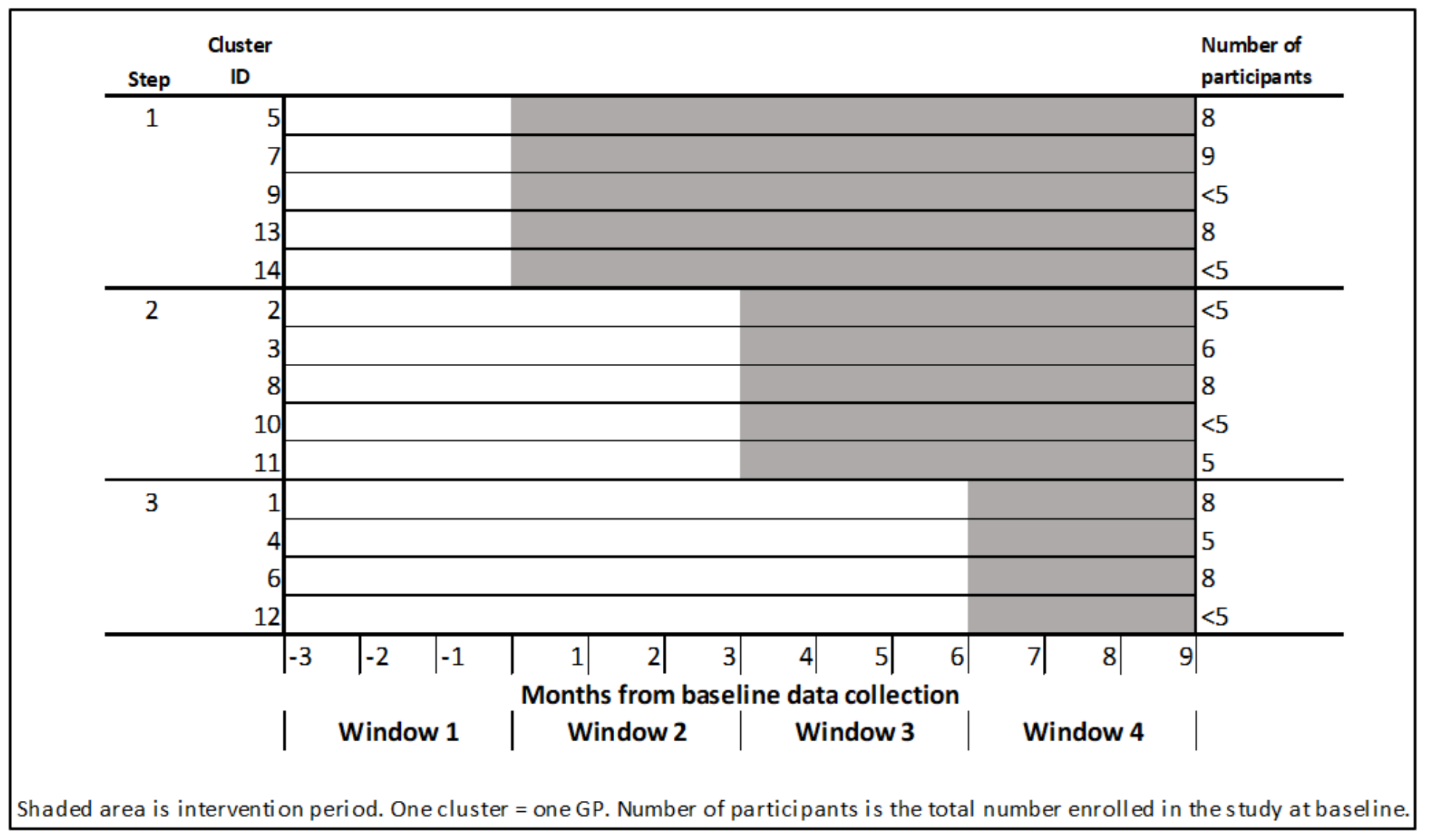

\section{Figure 2}

Roll-out diagram for the OPEN ARCH stepped wedge randomised controlled trial. 


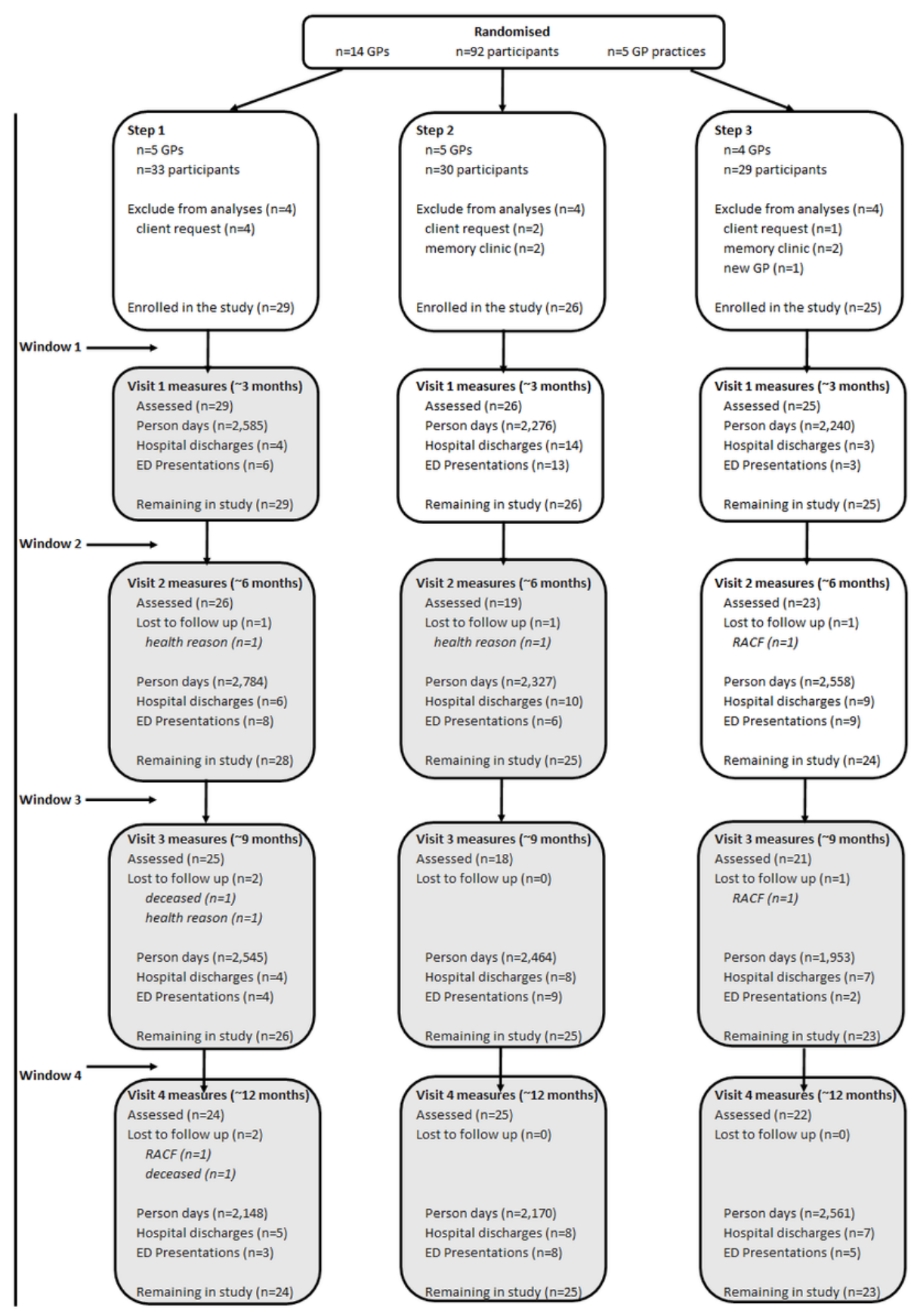

Figure 3

Randomisation and flow of participants during the OPEN ARCH study

\section{Supplementary Files}

This is a list of supplementary files associated with this preprint. Click to download.

- MANNSupplementaryTables.docx 